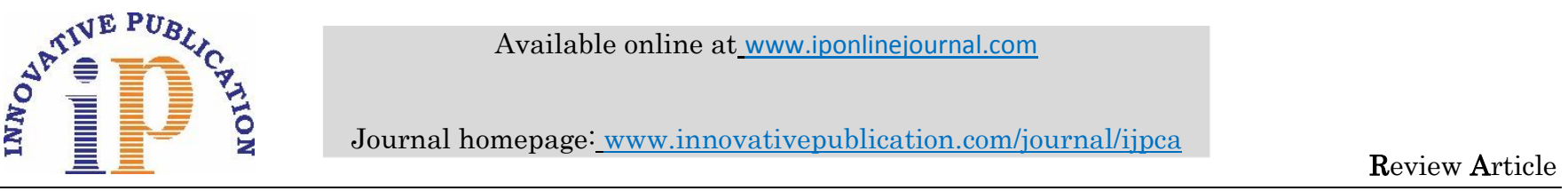

\title{
Medications mostly used in dentistry
}

\author{
Shaik Ali Hassan ${ }^{1 *}$, Sumit Bheteja ${ }^{2}$, Geetika Arora ${ }^{3}$ \\ ${ }^{1}$ Dental Surgeon, ${ }^{2}$ HOD,${ }^{3}$ Reader, ${ }^{2}$ Dept. of Oral Medicine \& Radiology, ${ }^{3}$ Dept. of Public Health Dentistry, ${ }^{1,2}$ Manav Rachna \\ Dental College, Faridabad, Haryana, ${ }^{3}$ Inderprastha Dental College \& Hospital, Ghaziabad, Uttar Pradesh, India
}

\begin{abstract}
There are many problems in relation to oral cavity which can be treated with use of drugs. There are problems like the oral diseases, to prevent or treat infections, or to control pain and relieve anxiety. Here is a review of the most commonly used medicines in dental clinic. The doses of the drugs and instructions on how to take them will differ from patient to patient, depending on what the drug is being used for, the patient's age and weight, and other considerations.
\end{abstract}

Keywords: Dental anesthetics include anbesol, Cloraseptic, Orajel and Xylocaine.

\section{Introduction}

Dentist prescribes a number of different medications, depending on the condition of the patient. Some medications are prescribed to fight certain oral diseases, to prevent or treat infections, or to control pain and relieve anxiety. The concentration of the drug is high instead of administration and will distribute nearby capillaries as long as the drug can penetrate local tissues as barriers. ${ }^{1}$ Dispersion of a drug from the bloodstream. Body tissue is called distribution. Because a medication is absorbed, its concentration in the blood, more precisely in the serum, get up and spread out of the capillaries towards the tissue. The speed and extent of drug administration are determined by the degree of perfusion of a given tissue and the solubility or affinity of the drug for tissue. ${ }^{2}$ Elimination refers to the elimination of the active substance in Circulation and is achieved either by excretion or by metabolism. Water soluble active ingredients they are usually excreted in the urine; This is described as a kidney. Fat soluble drugs are generally bio transformed into water soluble metabolites, which is possible then excreted in the urine. However, the liver is credited with the elimination of the drug because it eliminates the active drug by converting it into inactive metabolites is described as liver clearance. Although inactive metabolites remain in the serum and are not removed as such, the drug was still removed. The term divestment refers to the disposal of assets. ${ }^{3}$

There are various conditions for which medaction is used in dentistry:

1. Control fear and anxiety

2. Control plaque and gingivitis

3. Medications for prevention of tooth decay

4. Dry mouth

5. Antibiotics

6. Antifungals

\section{Control fear and anxiety}

Local anesthesia, general anesthesia, nitrous oxide or intravenous sedation are commonly used in dental procedures to relieve pain and anxiety. Other pain medications include prescription and non-prescription anti-inflammatory medications such as ibuprofen or pain relievers such as acetaminophen (Tylenol) and anesthetics (local or general).

Acetoaminophen is used in mild to moderate pain, with dosage of both acute and chronic doses of acetaminophen are associated with hepatotoxicity. For this reason, this drug has been reformulated so the products are limited to $325 \mathrm{mg}$ per dosage unit, adult dose of 325-650 mg every 4-6 hours. ${ }^{4}$ Corticosteroids are anti-inflammatory medications that are used to 
relieve the discomfort and redness of mouth and gum problems.

Corticosteroids are available by prescription only under such brand names as Kenalog in Orabase, Orabase-HCA, Oracort, and Oralone. Diphenhydramine hydrochloride and aluminum hydroxide, magnesium hydroxide, simethicone with dosage of Adults- $400 \mathrm{mg} /$ day. ${ }^{5}$ Use of Motrin, to relieve mild pain and/or swelling caused by dental appliances, toothaches, and fevers. Tylenol may also be given.

Dental anesthetics are used to relieve pain or irritation caused by many diseases, such as toothache, teething and sores in or around the mouth (cold sores, sores and cold sores, for example). These medications are also used to relieve pain or irritation caused by dentures or other dental tools, including braces. Anesthetics are available by prescription or over-thecounter and come in many forms, including spray, spray, toothpaste, gel, pills, ointments and solutions. Brand name products for dental anesthetics include Anbesol, Cloraseptic, Orajel and Xylocaine. Most benzocaine-containing medications for teething may be used in babies 4 months of age and older. Most of the other nonprescription medicines that contain a dental anesthetic should be used only in children 2 years of age and older. Also, because the elderly are particularly sensitive to the effects of many local anesthetics, they should not use more than is directed by the package label or the dentist. ${ }^{6}$

\section{Control plaque and gingivitis}

Chlorhexidine is an antibiotic that controls plaque and gingivitis in the mouth or in periodontal pockets. Chlorhexidine may cause an increase in tartar on your teeth, and may stain the tooth, tooth filling, and dentures or other appliances. adults: Rinse with $15 \mathrm{~mL}$ 2 times/day (after breakfast and before bed) for 30 seconds and expectorate. Brushing with a tartarcontrol toothpaste and flossing your teeth daily will help reduce this tartar buildup and staining.

\section{Medications for prevention of tooth decay}

Fluoride is used to prevent tooth decay and is available without a prescription in many tooth pastes. It is absorbed by the teeth and strengthens the teeth to allow them to resist acids and block the effect of urinating bacteria. Like nail polish or mouthwash, fluoride reduces the sensitivity of the teeth. Fluoride can cause discoloration of the teeth.

Prescription strength fluoride is available as a liquid, tablet and chewable tablet. It is usually taken once a day. It is prescribed to children and adults living in homes where the water is not fluoridated.

\section{Medications for prevention of tooth decay}

pilocarpine (Salagen) is the drug stimulates production of saliva. 5-mg pilocarpine tablets 4 times daily (20 $\mathrm{mg} / \mathrm{d}$ ) of dose is sufficient for the dry mouth. ${ }^{7}$

\section{Antibiotics}

tetracyclines (the class of drugs including demeclocycline, doxycycline, minocycline, oxytetracycline, and tetracycline) may be used alone or in combination with surgery and other therapies to Reduce or temporarily eliminate bacteria associated with periodontal disease, Suppress the destruction of the tooth's attachment to the bone, Reduce the pain and irritation of canker sores. Amoxycylin is used mostly with dosage of 250-500 mg every 8 hours and in case of endocarditis prophylaxis $50 \mathrm{mg} / \mathrm{kg}$ (maximum $2 \mathrm{~g}$ ) 30-60 minutes before procedure.,

Amoxicillin clavulanate potassium Use the lowest dose of clavulanate combined with amoxicillin available to decrease gastrointestinal adverse drug events. Usual oral dosage of 2-4, adults: $500-875 \mathrm{mg}$ every 12 hours. ${ }^{10}$ Cephalexin is antibiotic should not be prescribed to patients with Type I allergic reactions to penicillin antibiotics, Adults: $250-1,000 \mathrm{mg}$ every 6 hours (maximum $4 \mathrm{~g} /$ day). ${ }^{11}$

\section{Antifungals}

Antifungals are prescribed to treat oral thrush. Clotrimazole in form of Lozenge $10 \mathrm{mg}$, Dissolve one troche 5 times a day for 14 days. Treatment may extend beyond clinical resolution. Miconazole, in adults One tablet/day for 14 days; apply to the gum region, just above the upper lateral incisor. Nystatin in adults, Swish 400,000-600,000 units (4-6 mL) 4 times/day for several minutes and swallow; continue at least 48 hours after symptoms resolve. ${ }^{12}$ 


\section{Conclusion}

There are various medications for the use in the dentistry as they reduce the patients problems and they also help with the psychological state of the patient. So the drugs have to be given very cautiously and need to care of doses.

\section{Source of Funding}

None.

\section{Conflict of Interest}

None.

\section{References}

1. Buxton ILO. Pharmacokinetics and pharmacodynamics. In: Brunton LL, Lazo JS, Parker KL, eds. Goodman and Gilman's The Pharmacological Basis of Therapeutics. 11th edition. New York, NY: McGraw-Hill; 2006.

2. Wood M. Plasma binding and limitation of drug access to site of action. Anesthesiology. 1991;75:721-723.

3. Olin BR, Hebel SK, Dombek CE, eds. Drug Facts and Comparisons. 2006 ed. St Louis, MO: Facts and Comparisons, Inc; 2006.

4. American Academy of Pediatric Dentistry. Policy on acute pediatric dental pain management. Pediatr Dent 2018;40 (6):101-3

5. Jeske AH. Mosby's Dental Drug Reference. 12th edition. Elsevier, Inc., St. Louis, Mo., 2018.
6. Lexicomp Online, Pediatric and Neonatal Lexi-Drugs Online. Hudson, Ohio: Wolters Kluver Clinical Drug Information, Inc., 2018. Available at: "http://webstore.lexi.com/Pediatric-Lexi-Drugs". Accessed September 23, 2018.

7. Pilocarpine tablets for the treatment of dry mouth and dry eye symptoms in patients with Sjögren syndrome: a randomized, placebo-controlled, fixed-dose, multicenter trial. P92-01 Study Group, 25;159(2):174-81.

8. Lexicomp Online, Pediatric and Neonatal Lexi-Drugs Online. Hudson, Ohio: Wolters Kluver Clinical Drug Information, Inc., 2018. Available at:

"http://webstore.lexi.com/Pediatric-Lexi-Drugs". Accessed September 23, 2018.

"http://www.webcitation.org/6tmLOJRYJ")

9. Lexicomp Online, Lexi-Drugs Online. Hudson, Ohio: Wolters Kluver Clinical Drug Information, Inc., 2018.

10. Tobias JD, Green TP, Cote CJ, Section on Anesthesiology and Pain Medicine, AAP Committee on Drugs. Codeine: Time to say “no". Pediatr 2016;138(4):e20162396.

11. Wilson W. Taubery KA, Gewitz. Prevention of infective endocarditis: Guidelines from the American Heart Association. Circ 2007;116(15):1736-54. Correction: Circ 2007;116:e376-e377.

12. Montamat SC, Cusack BJ, Vestal RE. Management of drug therapy in the elderly. N Engl J Med 1989;321:303-9.

How to cite this article: Hassan SA, Bheteja S, Arora G. Medications mostly used in dentistry. Int J Pharm Chem Anal 2019;6(3):60-2. 